\title{
Experiences of breast cancer survivors during the COVID-19 pandemic: a qualitative study
}

\author{
Memnun Seven ${ }^{1}$ (1) $\cdot$ Gülcan Bagcivan ${ }^{2} \cdot$ Seyma Inciser Pasalak ${ }^{2} \cdot$ Gozde Oz $^{3} \cdot$ Yasemin Aydin $^{3} \cdot$ Fatih Selcukbiricik ${ }^{3,4}$
}

Received: 11 February 2021 / Accepted: 20 April 2021 / Published online: 27 April 2021

(c) The Author(s), under exclusive licence to Springer-Verlag GmbH Germany, part of Springer Nature 2021

\begin{abstract}
Purpose This study aimed to explore the impacts of the COVID-19 pandemic on the quality of life of breast cancer survivors. Methods This qualitative descriptive study included 18 breast cancer survivors who completed cancer treatment within the last five years in Istanbul, Turkey. A directed content analysis was performed using the quality-of-life domains as guiding themes.

Results The mean age was $51 \pm 5.9$, and the average months since active treatment were $26.5 \pm 9.8$ (9-48). Six themes and associated categories are as follows: Physical functioning; Changes in physical activity and weight, new physical symptoms, Role functioning; Work-life, changes in household chores, Emotional functioning; Emotional changes, fear of having the COVID-19 infection, Cognitive Functioning; Risk Perception about the COVID-19 infection, reactions to the COVID-19 pandemic' measures, Social Functioning; Familial relationship changes, social interactions, General Health/Utilization of Healthcare services; Changes in routine follow-ups, changes in diet.

Conclusion Breast cancer survivors had different challenges causing new physical and psychological symptoms such as lymphedema, pain, burnout, and anxiety that may have long-term effects on their quality of life.
\end{abstract}

Keywords Breast cancer $\cdot$ Survivors $\cdot$ The COVID-19 pandemic $\cdot$ Experience

\section{Introduction}

Healthcare systems and healthcare providers have been challenging with new cases of coronavirus and the contagious nature of the disease since the World Health Organization (WHO) declared the pandemic in February 2020 [1]. With the rapidly evolving COVID-19 pandemic worldwide, communities have practiced lockdowns, social distancing, and sheltering in place to "flatten the curve" to manage the rapid increase of the COVID-19 cases. Multiple uncertainties resulting from the pandemic negatively affect economic, political, and environmental issues globally [2]. These

Memnun Seven

memnunseven@gmail.com

1 University of Massachusetts Amherst College of Nursing, 230 Skinner Hall, 651 North Pleasant Street, Amherst, MA 01003, USA

2 School of Nursing, Koç University, Istanbul, Turkey

3 Koç University Hospital, Istanbul, Turkey

4 School of Medicine, Koç University, Istanbul, Turkey effects, along with the fear of COVID-19 infection, understandably caused anxiety, depression, and lower overall wellbeing among general populations [3]. Recent studies have highlighted the severe effects of the COVID-19 pandemic for all communities [2].

Although pandemic affects everyone at a different level, the challenges related to the pandemic can potentially jeopardize the lifetime wellbeing and quality-of-life (QOL) of individuals with cancer $[1,4]$. Emerging data suggest that individuals with cancer have an increased risk for the COVID-19 disease and risk of severe events such as admission to the intensive care unit requiring invasive ventilation or death due to COVID-19 [1, 4, 5]. Being an individual affected by cancer and needing healthcare during the pandemic became challenging due to the competing risks of cancer progression versus COVID-19 infection $[1,6]$. To minimize hospital visits and the risk of COVID-19 for cancer patients, diagnostic and surgical procedures were delayed, treatment plans were altered, and routine follow-up visits were postponed [6]. Healthcare providers have rapidly changed the model of care delivery [1, 7]. Telemedicine, remote monitoring, and home care were encouraged, and 
some medical and imaging services for people affected by cancer were re-organized to safely accommodate their needs [8].

Ultimately, the COVID-19 pandemic has disproportionately disrupted the lives of individuals affected by cancer, including those currently in treatment, those who completed treatment, and who are living cancer-free $[1,7]$. Currently, there is limited evidence regarding the impacts of the pandemic on cancer survivors, particularly those who have completed treatment [7]. As in many other types of cancer, there are also challenges in managing survivorship care of women affected by breast cancer due to the limited use of healthcare resources and the measures taken to minimize the risk of the COVID-19 infection during the pandemic [9]. Although women are increasingly surviving breast cancer, most breast cancer survivors experience long-term and late effects of cancer treatment even during the pre-pandemic period that dramatically impair the quality of life [10]. It created an urgent need to understand the impacts of the pandemic on breast cancer survivors and how these impacts can be addressed to minimize the late and long-term effects to optimize the QOL during survivorships.

Therefore, this qualitative study aimed to explore the impacts of the COVID-19 pandemic on the quality of life of breast cancer survivors.

\section{Methods}

\section{Design}

This qualitative descriptive study included semi-structured interviews among women affected by breast cancer who completed their medical treatment within the last 5 years. The study was approved by the Ethics Committee of the Koc University, Istanbul, Turkey.

\section{Sampling strategy}

A convenience sample of women was recruited among participants of a mixed-method study (unpublished study) to evaluate the QOL and needs of breast cancer survivors. The parent study's eligibility criteria included having a breast cancer diagnosis, completing the medical cancer treatments, being over 18 years old, speaking Turkish, and giving verbal consent. Twenty women had been recruited in November-December 2019 through the health record of an oncology clinic. Each woman who participated in that study was called to be invited to this current study. Women were informed about the study in May 2020, and a phone interview with the volunteers was scheduled. The total sample consisted of 18 women because one woman was deceased, and one woman could not be reached.

\section{Data collection}

We used a semi-structured interview guide to capture all experiences of women affecting their QOL during the pandemic. After the declaration of the COVID-19 pandemic on March 11th, 2020, Turkey had been on lockdown until the beginning of June 2020. One researcher (SIP) conducted recruitment and interviews in May 2020. The researcher (SIP) has been responsible for data collection with other researchers (GO, YA) in the parent study. The audio-recorded interviews lasted approximately 20-30 $\mathrm{min}$ and were transcribed verbatim.

\section{Analyses}

A directed content analysis [11] was performed using the guiding themes of the quality-of-life domains of the EORTC QLQ-C30 questionnaire [12]. The dimension of EORTC helped to determine the initial coding scheme. Two researchers (MS, GB) read the transcript and highlight all text that, on the first impression, appears to represent any QOL experiences during the COVID-19 pandemic. Then, the same researchers coded all highlighted passages and categorized them using the dimensions of the QOL. Any text that was not categorized with the initial coding was given a new code added to related dimensions of the QOL. The interactive process was conducted until the final codes/categories were established. The same researchers (MS, GB) reviewed the coding structure with the researcher (SIP) who conducted interviews to reach an agreement. In the final stage, a consensus for each code/ category was achieved among all researchers.

\section{Results}

\section{Patient characteristics}

All women had state health insurance covering survivorship care after the completion of medical cancer treatment. The mean age was $51 \pm 5.9$ (years), and the average months since the completion of their last chemotherapy were $26.5 \pm 9.8(9-48)($ Table 1$)$.

\section{The exploration of themes}

The themes, categories, and codes that emerged from the directed content analysis are given in Table 2 and Table 3 . 
Table 1 Descriptive characteristics of women affected by cancer

\begin{tabular}{|c|c|c|}
\hline$N=18$ & Mean \pm SD $(\min -\max )$ & $n(\%)$ \\
\hline Age (years) & $51 \pm 9.9(33-71)$ & \\
\hline Duration after the last chemotherapy (month) & $26.5 \pm 9.8(9-48)$ & \\
\hline Duration after the diagnosis (year) & $2.7 \pm 1.06(1-5)$ & \\
\hline \multicolumn{3}{|l|}{ Education attainment } \\
\hline Illiterate & & $1(5.6)$ \\
\hline Elementary school & & $4(22.2)$ \\
\hline High school & & $3(16.7)$ \\
\hline University and above & & $10(55.6)$ \\
\hline \multicolumn{3}{|l|}{ Employment } \\
\hline Employed & & $4(22.2)$ \\
\hline Not employed at all & & $4(22.2)$ \\
\hline Retired & & 7 (38.9) \\
\hline Quit job after a cancer diagnosis & & $3(16.7)$ \\
\hline \multicolumn{3}{|l|}{ Marital status } \\
\hline Married & & $12(66.7)$ \\
\hline Single & & $3(16.7)$ \\
\hline Divorced/separated & & $3(16.7)$ \\
\hline \multicolumn{3}{|l|}{ Household } \\
\hline Living alone & & $3(16.7)$ \\
\hline Living with husband & & $3(16.7)$ \\
\hline Living with children & & $1(5.6)$ \\
\hline Living with husband and children & & $9(50)$ \\
\hline Living with mother or sibling & & $2(11.2)$ \\
\hline \multicolumn{3}{|l|}{ Insurance } \\
\hline State health insurance & & $16(88.9)$ \\
\hline State health insurance and Private insurance & & $2(11.1)$ \\
\hline \multicolumn{3}{|l|}{ Chronic disease } \\
\hline No & & $13(72.2)$ \\
\hline $\begin{array}{l}\text { Yes (hypothyroid, diabetes mellitus, hypertension, } \\
\text { arrhythmias) }\end{array}$ & & $5(27.8)$ \\
\hline \multicolumn{3}{|l|}{ Use of hormone therapy } \\
\hline Yes & & $15(83.3)$ \\
\hline No & & $3(16.7)$ \\
\hline \multicolumn{3}{|l|}{ The stage at the diagnosis } \\
\hline Stage I & & $3(16.7)$ \\
\hline Stage II & & $6(33.3)$ \\
\hline Stage III & & $8(44.4)$ \\
\hline Stage IV & & $1(5.6)$ \\
\hline
\end{tabular}

The quotations from participants are given with an identity document (ID) number to preserve anonymity.

Theme 1: Physical functioning includes the ability to perform daily living activities and changes affecting their ability to perform activities of daily living.

Changes in physical activity and weight While almost all women complained about the limited physical activity, some women stated that they could find new ways to stay active such as walking in the home or the garden, starting yoga or mediation, and attending online exercise classes. One woman who bought a treadmill during the lockdown stated, "I bought a treadmill in the first week. I do sports better than before, and I do yoga. I'm doing breathing techniques" (ID-2).

However, women appeared to be concerning about their physical health due to the extended lockdowns. Of women, eight mentioned their weight gain threatening their health and daily life. One woman expressed her concern, "I mean, 
Table 2 The themes, categories, and codes

\begin{tabular}{|c|c|c|}
\hline Themes & Categories & Codes \\
\hline \multirow[t]{2}{*}{ Physical functioning } & Changes in physical activity and weight & $\begin{array}{l}\text { Limited physical activity } \\
\text { New ways of physical activity } \\
\text { Concern about physical health } \\
\text { Weight gain }\end{array}$ \\
\hline & New physical symptoms & $\begin{array}{l}\text { Lymphedema } \\
\text { Fatigue } \\
\text { Eczema } \\
\text { Bone pain/tingling }\end{array}$ \\
\hline Role functioning & $\begin{array}{l}\text { Work-life } \\
\text { Changes in household chores }\end{array}$ & $\begin{array}{l}\text { Continue to work } \\
\text { Increase/new distribution in household tasks }\end{array}$ \\
\hline \multirow[t]{2}{*}{ Emotional functioning } & Emotional changes & $\begin{array}{l}\text { Anxiety/feeling oversensitive } \\
\text { Emotional burnout }\end{array}$ \\
\hline & Fear of having COVID-19 & $\begin{array}{l}\text { Having psychosomatic symptoms } \\
\text { Constant check symptoms } \\
\text { Worry about children's health }\end{array}$ \\
\hline \multirow[t]{2}{*}{ Cognitive functioning } & Risk perception about COVID-19 infection & $\begin{array}{l}\text { Perceived high risk of getting COVID-19 } \\
\text { Uncertainty about the high risk of getting COVID-19 } \\
\text { No high risk perceived }\end{array}$ \\
\hline & Reactions to the COVID-19 pandemic measures & $\begin{array}{l}\text { Continues/strict observance of the COVID-19 measures } \\
\text { Struggling to observe the COVID-19 measures at home } \\
\text { Feeling prepared for COVID-19 measures } \\
\text { Having life as possible as normal } \\
\text { Reflecting on her life }\end{array}$ \\
\hline \multirow[t]{2}{*}{ Social functioning } & Familial relationship changes & $\begin{array}{l}\text { Increased time spent with family members } \\
\text { Continues warning from family member to observe measures } \\
\text { Having a family member with COVID-19 } \\
\text { Performing social distancing at home }\end{array}$ \\
\hline & Limited social interaction & $\begin{array}{l}\text { Continuing not to accept anyone at home } \\
\text { New ways to communicate with friends }\end{array}$ \\
\hline \multirow[t]{2}{*}{$\begin{array}{l}\text { General health/utilization } \\
\text { of healthcare services }\end{array}$} & Changes in routine follow-ups & $\begin{array}{l}\text { Postponing/thinking of postponing the routine health follow-ups } \\
\text { No cancelation with continuing with the previous schedule } \\
\text { Changes in the healthcare setting } \\
\text { Worry about (upcoming) follow-up in the hospital }\end{array}$ \\
\hline & Changes in diet & $\begin{array}{l}\text { Developing a healthier diet } \\
\text { Using the vitamin/nutrition supplements }\end{array}$ \\
\hline
\end{tabular}

after a while, the fear of physical health gets ahead from psychological problems because of staying all the time indoors... Even if I do exercise, I think it affects negatively because space is limited at home" (ID-12).

New physical symptoms Lymphedema, fatigue, eczema, and bone pain/tingling were reported that developed during the COVID-19 pandemic. Lymphedema was reported due to increased household chores; that woman mentioned she could not go to the hospital yet for her painful lymphedema. This woman stated that "My arm was swollen because I did too much work (chores) at home, and then my left arm was swollen so bad. In fact, I will go to the lymphedema department for it, so I sometimes have pain on my left side... I also have a lot of back pain, so how can I tell you, my purse even is getting too heavy" (ID-4).

Due to increased chores and lack of physical activity, some women mentioned their increased fatigue. One woman stated that due to stress and washing hands more often, she developed eczema. Some women developed bone pain and tingling due to decreased physical activity or vitamin D deficiency caused by limited sunlight exposure as they reported.

Theme 2: Role functioning includes any involvement in life situations related to work-life, studies, and everyday living activities. 
Table 3 Description of the themes, categories, and codes

Themes Categories Codes and one example of the quotes

Physical functioning Changes in physical activity and weight

New physical symptoms

Role Functioning

Work-life

Changes in household chores
Limited physical activity (all mentioned it)

"Unfortunately, because of staying at this home all the time. For example, I gained three or four kilos due to inactivity. Now I'm trying to give them. I'm sitting on an apartment complex, so it is more likely for me to be able to take a walk around" (ID-13)

New ways of physical activity $(n=5)$

"I bought a treadmill in the first week. I do sports better than before; I do yoga. I'm doing breathing techniques" (ID-2)

Concern about physical health $(n=3)$

"I mean, after a while, the fear of physical health gets ahead because of staying indoors, from psychological problems. So, I think it affects negatively even if I do physical exercise because space is limited at home" (ID-12)

Weight gain $(n=7)$

"I gained four kilos. I can't do my walk much now. I mean, I was doing more physical activities before, I was like in prison, so it was restricted at home. However, it (doing activities at home) is not like the one you do outside of the house" (ID-10)

Lymphedema $(\mathbf{n}=\mathbf{1})$

"My arm was swollen because I did too much work (chores) at home, and then my left arm was swollen so bad. In fact, I will go to the lymphedema department, so I sometimes have pain on my left side. This is how things happen when I turn left suddenly on my surgery side. I have stabbing pain. I also have a lot of back pain, so how can I tell you, my purse even is getting too heavy" (ID-4)

Fatigue $(\mathbf{n}=2)$

"I mean, if the slightest wind blows, how can I tell you immediately, my body starts to be hurt. So I guess my immune system has weakened anyway. So when I do something, I get tired very quickly. I need to rest on the sofa, to rest" (ID-4)

Eczema $(\mathbf{n}=\mathbf{1})$

"My hands became like getting eczema because of washing both my hands and the vegetables. However, it is just over. From washing, cleaning, wiping ... I guess that period increased my stress a little bit. People are worried about whether something will happen to their loved one, will something happen to my relatives" (ID-4)

Bone pain/tingling $(n=2)$

"Walking was very important for me; now, my bones were causing some trouble. My knees started to ache. Pain under my feet, the pain started in my arm. Then I have started yoga. I saw so many benefits after starting yoga" (ID-7)

Continue to work $(n=2)$

"For the first twenty days, I did not go out on the field (for field reconnaissance). My children said, -mom, please don't go. Your health is important-. But one month later, I thought I wouldn't be able to stay home. Believe me, the field is no more dangerous than walking around the city. We're going with two experts; the field has plenty of oxygen" (ID-8)

Increase/new distribution in household tasks $(n=2)$

"At that time, of course, we could not get a housekeeper or something. Of course, my arm was swollen. Almost how can I tell you; my arm became as near as the thickness of my legs, I wear thirtyeight size (in clothing), it was like that big of the upper leg" (ID-3) 
Table 3 (continued)

Themes Categories

Codes and one example of the quotes

Emotional Functioning Emotional changes

Fear of having COVID-19

Anxiety/feeling oversensitive $(n=2)$

"Of course, there is a nervousness in people. Maybe if I did not have such a disease, if I had continued my life as a normal person as before, maybe I would not have been isolating myself so much. You know, I postponed many things I have to do. So if it weren't like that, maybe I would be a little more comfortable" (ID-7)

Emotional burnout $(n=2)$

"I never leave the house, except for the hospital. I always keep my gloves, mask, and distance while out. I disinfect myself. But here we are stuck in the houses. I never went out because I was chronically ill. I guess that thought made me collapse. I had to take a walk. I had to let off steam. Unfortunately, we're stuck inside" (ID-15)

Having psychosomatic symptoms $(n=3)$

"Of course, it devastated my psychology like everyone else. A constant throat burning, headache, I wonder whether I get infected or not, I mean somehow. I even thought about having a test, but when there is no fever, they do not do it. I suppose all because of my psychology" (ID-17)

Constant check symptoms $(n=3)$

"After a while, I overcame it, but at first, I was also measuring both my own temperature and my kid's temperature with a thermometer in my hand for the first or two weeks or so, since this little one had a low immunity syndrome" (ID-14)

Worry about children's health $(n=1)$

"I am worried more for my children than for myself because my children are younger. It is very difficult to protect them. So, they touch everywhere; they try to reach everyone. You know, I'm more worried about them" (ID-7) 
Table 3 (continued)

\begin{tabular}{ll}
\hline Themes & Categories \\
\hline Cognitive Functioning & Risk perception about COVID-19 infection
\end{tabular}

Codes and one example of the quotes

Perceived high risk of getting COVID-19 $(n=11)$

"Of course, compared to normal people, I thought that the risk is higher to get the disease for me because I have learned from experience, even if it is not COVID. It felt like I could get caught more easily than the others. But I was very careful. In fact, my elder son was saying that as long as my mother is in this house, it (COVID19) cannot come here" (ID-14)

Uncertainty about the high risk of getting COVID-19 $(n=3)$

"We can't know anything. So, is my risk high or low right now? Of course, we are among the risky ones, after all of our diseases, right? I wouldn't know this before I live. More precisely, when I come across something like this virus. I wonder if my immunity is strong. For example, when my immunity gets back to a normal level, it has been two years since I received chemotherapy. For example, I don't know if my immune system is good right now. I look at my blood test results; the results of my blood test are normal. But I don't know if this shows my immune system" (ID-13)

No high risk perceived $(n=2)$

"No, I do not think. I think my immunity is good. Even if I go out anyway, I go to nearby places to get a prescription, and I use my mask. I pay attention to hygiene" (ID-18)

Reactions to the COVID-19 pandemic measures

"We washed our hands, and then we wiped the door handles constantly. Only my husband and I, no children, and we did not have any contact with anyone else outside. We're locked up here. The Municipality always called us, asked about our wellbeing and our situation. There are acquaintances there, and they did our shopping. Except that, for example, I put bread on the fire a little bit, then I put them in the kitchen. I emptied the shopping bags after keeping them on the balcony for two or three days" (ID-3)

Struggling to observe the COVID-19 measures at home $(n=2)$

"So how do you maintain your social distance with the person you live with in the same house. If one sneezes, they say that I can pass it on; they say if you pass through there, you can catch it. It does not seem real to me. We do not sit, after all, but it does not seem very convincing. God forbid, if something happens to one of us in the same house, I don't think the other will escape from it (COVID19)" (ID-11)

Feeling prepared for COVID-19 measures $(n=1)$

"Well, since I have been treated for breast cancer for fifteen months, I had to have limited life while taking chemo, even at home after an intense chemotherapy and radiotherapy process. So let me say I am ready to stay at home. You have to protect yourself very well during chemo. You cannot accept visitors too, except your immediate family, so you have to manage by phone or something to connect them" (ID-16)

Having life as possible as normal $(n=3)$

"If you say how much you did, I followed 60 percent of the measures. I did the shopping myself. Completely went back and forth, washed my hands, took my shower, as much as I could, but forty percent of my life was normal" (ID-17)

Reflecting on her life $(n=1)$

"I mean, it gave us the opportunity to listen to our inner voice like what I am doing, after all, that, how do I live or something like that, thinking about your life" (ID-2) 
Table 3 (continued)

\begin{tabular}{ll}
\hline Themes & Categories \\
\hline Social Functioning & Familial relationship change
\end{tabular}

\section{Increased time spent with family members $(n=2)$}

"I was impacted like everyone else. Maybe I also saw some of the beautiful aspects of it; my husband was such a busy person who stayed at home a little more during this period. It was good for us. So I'm trying to look at the bright side. You know, I didn't stay inactive at home. I also have a child with down syndrome; we took care of him more when there was an epidemic at home" (ID-14)

Continues warning from family member to observe measures $(\mathbf{n}=2)$

"My daughter says, if you get it (COVID-19), you cannot survive. I am seventy-one seventy-two, so whatever we live more is a profit. She called me today, keep saying do not get closer with people, keep your distance, so she says,--I know our people, they say welcome and get closer to you, my daughter takes it seriously. She says, your life depends on it, if you caught it, you could not survive" (ID-3)

Having a family member with COVID-19 $(n=1)$

"When my son had COVID, we separated his room, his toilet. Is it possible to get your child completely quarantined at all? But there comes a moment when you say that if I will, it doesn't matter. Your eyes don't see anything at that moment" (ID-17)

Performing social distancing at home $(n=1)$

"I have one son at home. My other sons live downstairs, but when they go to work or something, they don't come to my house. They are also paying attention to that. My little boy quarantines himself in his room when he goes out" (ID-18)

Continuing not to accept anyone at home $(n=3)$

"So, I still stay at home. We do not see anyone else; we even did not go to our summer house. We don't go to the market. Everything comes with cargo. We take them in and constantly disinfecting them. Only our father goes out. He also provides our necessary needs. Are we afraid? I am twice as scared as other people. But somehow, it seems necessary to move to normalization. But I know now we will never be able to return to the old normal" (ID-7)

New ways to communicate with friends $(n=1)$

"Yes, we meet with my friends once a week via zoom. We talk to my daughter and my relatives via phone again. We hold zoom meetings. The process was not dramatic for us, not like my life is ruined- Let me tell you this, we are people of lucky ages. We do not have financial difficulties; we have a regular income. We have no children that I have to take care of at home" (ID-2) 
Table 3 (continued)

\begin{tabular}{ll}
\hline Themes & Categories \\
\hline $\begin{array}{l}\text { General health/utiliza- } \\
\text { tion of healthcare }\end{array}$ & Changes in routine follow-up \\
services &
\end{tabular}

Changes in diet

Continue to work Although there are four women employed at the time of the interview, two of them mentioned that they preferred to continue working with measures that they took for the COVID-19 pandemic. However, one woman mentioned having constant warnings from her children and husband for not continuing to work due to the fear of CVOID-19.

Changes in household chores In general, women reported new distributions of household tasks at their homes. Some had their husbands or children go shopping; some only did online shopping to minimize COVID-19 exposure. Two women stated that their household chores increased because
Codes and one example of the quotes

Postponing/thinking of postponing the routine health follow-ups $(\mathbf{n}=12)$

"On March 30, our three months period was over, they postponed it to April first, and the April appointment was postponed to May. Because there were patients in the hospital with COVID. They said the virus load was too high. I made my there-months check up on May 11. After that day, like a rabbit came out of a hat, that pain showed up, so what can we do?" (ID-16)

"For now, I hope I will call my doctor. If he says come, I will, but if he says not, to be honest, I do not think I will go to the hospital. When I go to the hospital, I get a completely different interest because of the Corona. I am not fully examined at, something is thrown into the Corona immediately as if you had Corona. I experienced that" (ID-10)

No cancelation with continuing with the previous schedule $(n=4)$

"I had to come to the hospital for my three-month routine checkup. Then I came last month. X-ray was taken, and a tomography was done, my ultrasound was done last month. They said my tomography and my mammography result were good for the last month. Today I got the result of what it's called radiation. Not radiation. I forget what I'm talking about. They also said let's do a tomography. My intestines were checked too. He said there was a bleeding in the lung. He said there is a suspicious situation in his thyroid too, I will come again" (ID-15)

Changes in the healthcare setting $(n=1)$

"For my breast cancer routine controls, there are breast ultrasound and lung x-ray. There is an imagining center, which only does $\mathrm{x}$-rays, and it makes sense to me that COVID patients do not go there to get their fever measured" (ID-16)

Worry about (upcoming) follow-up in the hospital $(n=4)$

"For the checkup that I was supposed to go in April, I went in May, I gave blood test several times from home, I had to go to the hospital but let me say that it was as 'a shiver went down my spine"” (ID-12)

Developing a healthier diet $(n=3)$

“Obviously, I changed my diet completely. So, I wasn't having sugar and flour anyway, but now I am paying much more attention. We cut the packed food completely. In other words, I try not to buy anything from outside, not even bread" (ID-7)

Using the vitamin/nutrition supplements $(n=4)$

"I get some support with turmeric. I also drink propolis. I have been drinking propolis from the very beginning and I think it is good for my immunity" (ID-11) of not having regular housekeeping that they usually had. This increased work led to some new symptoms, including a newly developed lymphedema and fatigue.

Theme 3: Emotional functioning includes specific reactions to the COVID-19 pandemic and related measures.

Emotional changes Anxiety, being oversensitive, and burnout were the emotional changes women reported. Although women acknowledged that the pandemic is stressful for everyone, as a person affected by cancer, they felt more emotions involved during the pandemic than other people. One 
woman described how emotional/oversensitive she felt by saying, "If someone said, "go a little further," I would cry. I mean, my psychology is broken. I even thought of going to a psychologist during this period. Of course, I couldn't go because it was not allowed" (ID-17). Another woman expressed how she felt emotionally worn out "I never leave the house, except for the hospital. I always keep my gloves, mask, and distance while out. I disinfect myself. But here we are stuck in the houses. I never went out because I am chronic ill. I guess that thought made me collapse..." (ID-15).

Fear of having COVID-19 Three women described psychosomatic symptoms related to their fear of CVODI-19 infection. Although they acknowledged that this is temporary due to the pandemic, women appear to be still struggling to overcome their fear. In addition to constant heavy cleaning at home, some women reported that they kept checking their self and their children's health to detect symptoms early if it happens. Even one woman expressed her worry for her children by saying, "I am worried more for my children than myself because my children are young. It is very difficult to protect them..." (ID-7).

Theme 4: Cognitive functioning includes any reactions that involve knowledge, information, reasoning, and reactions to the COVID-19 pandemic and its measures.

Risk perception about COVID-19 infection Although most women perceived high risk for COVID-19 infection, three women appeared confused. Two women reported that they did not see any increased risk for themselves; however, they followed the recommendations for the COVID-19 infection.

Those with uncertain or not seeing any high risk referred to their immune system as a rationale for their thoughts. One woman said, “... Of course, we are among the risky people, after all of our diseases, right? ... I wonder if my immunity is strong. When my immunity gets back to a normal level, it has been two years since I received chemotherapy. I don't know if my immune system is good right now. I look at my blood test results; the results of my blood test are normal. But I don't know if this shows my immune system." (ID-13).

Reactions to COVID-19 measures Most women stated that they all observed the recommended measures related to the pandemic, such as washing hands, wearing a mask, and performing social distancing. Most women also reported strict hygiene practices, such as cleaning the home often, washing, or keeping shopping bags outside before placing them in the kitchen. However, some expressed their struggles in understanding and observing the COVID-19 measures at home. One woman stated that "So how do you maintain your social distance with the person you live with in the same house. If one sneezes, they say that it can be passed on; they say if you pass through there, you can catch it too. It does not seem real to me." (ID-11).

Some women reported that they tried to live their life as normal as possible. Because women needed to go to the hospital for their follow-up visits or other health issues, they had to live with COVID-19 restrictions. Some women felt ready to take the COVID-19 measures, including staying at home and wearing a mask due to their chemotherapy experiences. One woman stated that "So we have been wearing a mask for a year anyway. My kids have bought a face shield too. I need to get my port flushed every six weeks. I could postpone it, but COVID has been overflowing at this time, and I had to go at the end" (ID-16). One woman also stated that she had the opportunity to listen to her inner voice to reflect on her life during the quarantine.

Theme 5: Social functioning includes women's ability to fulfill their social activities and relationships with family.

Familial relationship changes Increased time spent with family, having a continuous warning about protecting themselves from the COVID-19 infection, performing social distancing at home, and having children infected by COVID-19 were some experiences reported by the women. One woman repeatedly reported that her daughter kept warning about the measurements of COVID-19. One woman shared her experience of having her children infected by the COVID19 and how she focused on her children's life at that time and ignored her own health. In addition to these unpleasant experiences, one woman was pleased to spend more time with her husband and children with Down syndrome.

Limited social interaction Generally, women did not accept visitors and went out only for essential needs during the pandemic. One woman described the measures taken in her workplace; some women had their husbands or children shopped for them or did online shopping with strict cleaning. One woman who was observing the measurements stated that "so I still stay home... Only my husband goes out to provide our necessary needs. Are we afraid? I am twice as scared as other people. But somehow, it seems necessary to move on with some normalization" (ID-7).

Theme 6: General health/health service utilization includes routine follow-ups and general healthy behaviors develop during the pandemic.

Changes in routine follow-ups Six women stated their routine follow-up appointments had been canceled and 
rescheduled. Six women had no cancelations and would follow their hospital appointments as planned before the pandemic. Four women stated that no appointments canceled yet, but they did not think of going to the hospital due to fear of COVID-19 infection. Most women appeared unwilling to go to the hospital and concerned about being at the hospital due to the high risk of COVID-19 exposure. However, two women appeared to be willing to come to the hospital on a scheduled day, emphasizing the need for having USG and other blood tests.

Four women had upcoming appointments and been thinking of either talking with their physician to decide or not coming to their hospital visit. One woman concerned about not being treated well as she was before the pandemic stated, "I will call my doctor. If he says come, I will, but if he says not, to be honest, I do not think I will go to the hospital. When I go to the hospital, I get a completely different interest because of the Corona. I am not thoroughly examined; something is thrown into the Corona immediately as if you had Corona" (ID-10).

One woman shared her feelings about having two options instead of having one recommendation on what to do, including to cancel or come to her appointment. She stated, "it appears to me so weird that I was told that the physician sees his patients, you can decide whether you want to come or postpone your appointment. I expected it to be canceled by the hospital. I struggled on rescheduling it at the end" (ID-13).

Changes in the diet Three women had changed their diet entirely or to a greater extent. Four women started taking supplements such as vitamin $\mathrm{D}$, vitamin $\mathrm{C}$, propolis, multivitamins, mineral, and ginseng supplements.

\section{Discussion}

Many cancer survivors have fatigue, sleep problems, impaired physical functioning, pain, and several physical symptoms [13] that impair their QOL. In this study, breast cancer survivors reported new symptoms that occurred during the pandemic, mostly due to physical inactivity, increased household chores, or stress experienced during the pandemic. Lymphedema, eczema, increased fatigue, general pain, bone pain, and tingling were the physical symptoms women suffered. Similarly, Helm et al. reported that primary complaints of women affected by breast cancer during the closure of rehabilitation services due to the COVID-19 pandemic were shoulder stiffness, pain, and lymphedema [14]. Miaskowski et al. reported that the majority of the cancer patients had evening fatigue (55.9\%), cognitive impairment $(91.5 \%)$, and pain $(75.9 \%)$ during the pandemic in a sample with $80 \%$ of breast cancer patients [15]. Although some women expressed constant bone pain and tingling due to lack of exercise and physical activity, some could find new ways to stay active. Some women started yoga, meditation, signed up for an online exercise group, and even bought a treadmill to exercise at home. Cancer survivors need to incorporate targeted and individualized exercise, which can significantly reduce morbidity and mortality of cancer [16].

In this study, weight gain was a big concern for most cancer survivors due to lack of physical activity during the lockdown. Weight gain is a common problem for breast cancer survivors and can cause adverse health outcomes. Few women reported developing a healthy diet, and some women started using supplements such as vitamin D, vitamin C, propolis, and multivitamins, mineral, and ginseng supplements to boost their immune system to prevent COVID-19 infection. Regarding individuals affected by cancer, there is a concern about the overuse of supplements, specifically antioxidants, which have been promoted to prevent and treat COVID-19 infection [17]. Although some women in this study mentioned their physician to consult before using any supplements, this study shows the need for nutrition care for those affected by cancer to educate them about a healthy diet and supplements based on evidence.

One woman had developed lymphedema during the pandemic and could not have healthcare for this problem. Some evidence suggests that specific exercises may reduce the risk and severity of lymphedema $[16,18]$. However, when left unmanaged, lymphedema can cause chronic inflammation, increased risk of tissue fibrosis, infection, and impaired wound healing [14]. As alternative care models, telehealth/ remote care delivery for survivorship are recommended to support patients living with the late and long-term effects of cancer treatment. During the pandemic, telehealth was encouraged [8]; however, since it requires structure and technology to offer, telehealth has not been available in many healthcare settings. In this study, no women mentioned any telehealth utilization for their follow-up care. Helm et al. reported that $33 \%$ of women with shoulder stiffness, pain, or lymphedema had received telehealth [14]. Incorporating psychologically informed physical therapy through telehealth might be an option to support cancer survivors for healthy nutrition and physical activity to manage fatigue, sleep problems, and stress related to the pandemic [14].

Although two women mentioned positive aspects of being at home and spent more time with loved ones, anxiety, feeling oversensitive, and emotional burnout were the psychological effects of the COVID-19 pandemic that women described in this study. Emotional challenges appeared to be more intense and unbearable due to not having access to psychological support and activities to ease their emotions. The pandemic appeared to have created additional stress and anxiety among breast cancer survivors. In another study, 51.4\% of women with ovarian cancer had anxiety, and $26.5 \%$ had 
depression during the COVID-19 pandemic [19]. Similarly, Miaskowski et al. reported that $31.6 \%$ of cancer patients had high-stress scores, and cancer patients exceeded previous benchmarks in oncology patients meaning possible PTSD. In this stressed group, patients also reported depression (71.2\%), anxiety (78.0\%), and sleep disturbance (78.0\%) [15]. Although no women reported social isolation or loneliness, limited social interactions may cause loneliness and impaired psychological well-being that cancer survivors can even experience before the COVID-19 pandemic [20]. These findings show the urgent need for innovative ways to tackle these psychological problems and their long-term effects as the pandemic has been evolving.

In the study, most women had delays or cancelations in follow-up visits. While they were trying to make the best decision for themselves, some women expressed anxiety about going to the hospital due to high infection risk and some expressed the frustration of making decisions on their hospital visit. Frey et al. reported that $33 \%$ of women with ovarian cancer experienced a delay in some components of their cancer care [29]. Some recent guidelines provide recommendations that help healthcare providers $[1,8,21]$ in decision-making on cancer care during the pandemic. Unfortunately, there are no specific guidelines for cancer survivors who completed their medical treatment. As the pandemic continues to evolve and evidence increases, more specific recommendations and guidelines are needed for the cancer survivors addressing their QOL [7]. Nurses have a crucial role in developing survivorship care guidelines and creating alternative care models for cancer survivors during and beyond the pandemic. The use of alternative care models led by nurses such as shared care, nurse-led care, and self-management may free up oncologists to focus on acute patients requiring urgent care and reduce the risk for COVID-19 exposure by minimizing unnecessary presentations to acute care facilities [22].

\section{Conclusion}

Alternative healthcare delivery models for cancer survivors are needed to ensure that patients are least affected by this pandemic. Physical health challenges, including increased weight and lack of physical activity, and symptoms such as lymphedema, pain, and fatigue need to be addressed to prevent their long-term effects on QOL among breast cancer survivors. The psychological effects of the pandemic, such as depression and anxiety, may also impair long-term QOL if not addressed. As pandemic evolves into different stages, oncology nurses in a collaboration with multidisciplinary oncology team need to show leadership in managing the pandemic in oncology settings and meeting the needs of individuals affected by cancer during the health crisis. While we need to assess the immediate impacts of the COVID-19 pandemic, further studies are recommended focusing on the long-term effects of the pandemic on different aspects of QOL among cancer survivors.

\section{Limitations}

Convenience sample of breast cancer survivors may affect the participants' responses and limit the generalizability of findings to people affected by different cancer types. Data were gathered at a specific point of time, which does not capture women's dynamic experiences as the pandemic evolves.

Author contribution All authors contributed to the study conception and design. Material preparation, data collection (Seyma Inciser Pasalak), and analysis were performed by Memnun Seven, Gulcan Bagcivan, and Seyma Inciser Pasalak, the first draft of the manuscript was written by Memnun Seven and Gulcan Bagcivan, and all authors commented on previous versions of the manuscript. All authors read and approved the final manuscript.

Data availability All the data that collected from the study is present.

Code availability Not applicable.

\section{Declarations}

Ethics approval This study was performed in line with the principles of the Declaration of Helsinki. Approval was granted by the Ethics Committee of Koç University.

Consent to participate Verbal informed consent was obtained from all individual participants before the interview.

Consent for publication Verbal informed consent was obtained from all individual participants before the interview, and all the participants were aware of the data that had been collected would use for scientific publications.

Conflict of interest The authors declare no competing interests.

\section{References}

1. Kutikov A, Weinberg DS, Edelman MJ, Horwitz EM, Uzzo RG, Fisher RI (2020) A war on two fronts: cancer care in the time of COVID-19. Ann Intern Med 172(11):756-758. https://doi.org/10. 7326/m20-1133

2. El Keshky MES, Basyouni SS, Al Sabban AM (2020) Getting through COVID-19: the pandemic's impact on the psychology of sustainability, quality-of-life, and the global economy - a systematic review. Front Psychol 11:585897. https://doi.org/10.3389/ fpsyg.2020.585897

3. Young AM, Ashbury FD, Schapira L, Scotte F, Ripamonti CI, Olver IN (2020) Uncertainty upon uncertainty: supportive care for cancer and COVID-19. Support Care Cancer 28(9):4001-4004. https://doi.org/10.1007/s00520-020-05604-9 
4. de las Heras B, Saini KS, Boyle F, Ades F, de Azambuja E, Bozovic-Spasojevic I, Romano M, Capelan M, Prasad R, Pattu P, Massard C, Portera C, Saini ML, Singh BP, Venkitaraman R, McNally R, Leone M, Grande E, Gupta S (2020) Cancer treatment and research during the COVID-19 pandemic: experience of the first 6 months. Oncol Ther. https://doi.org/10.1007/s40487-020-00124-2

5. Liang W, Guan W, Chen R, Wang W, Li J, Xu K, Li C, Ai Q, Lu W, Liang H, Li S, He J (2020) Cancer patients in SARS$\mathrm{CoV}-2$ infection: a nationwide analysis in China. Lancet Oncol 21(3):335-337. https://doi.org/10.1016/s1470-2045(20)30096-6

6. Miaskowski C, Paul SM, Snowberg K, Abbott M, Borno H, Chang S, Chen LM, Cohen B, Cooper BA, Hammer MJ, Kenfield SA, Laffan A, Levine JD, Pozzar R, Tsai KK, Van Blarigan EL, Van Loon K (2020) Oncology patients' perceptions of and experiences with COVID-19. Support Care Cancer. https://doi.org/10.1007/ s00520-020-05684-7

7. Nekhlyudov L, Duijts S, Hudson SV, Jones JM, Keogh J, Love B, Lustberg M, Smith KC, Tevaarwerk A, Yu X, Feuerstein M (2020) Addressing the needs of cancer survivors during the COVID-19 pandemic. J Cancer Surviv 14(5):601-606. https://doi.org/10. 1007/s11764-020-00884-w

8. Moujaess E, Kourie HR, Ghosn M (2020) Cancer patients and research during COVID-19 pandemic: a systematic review of current evidence. Crit Rev Oncol Hematol 150:102972. https://doi. org/10.1016/j.critrevonc.2020.102972

9. Citgez B, Yigit B, Capkinoglu E, Yetkin SG (2020) Management of breast cancer during the COVID-19 pandemic. Sisli Etfal Hastanesi Tip Bulteni 54(2):132-135. https://doi.org/10.14744/ SEMB.2020.23326

10. Lovelace DL, McDaniel LR, Golden D (2019) Long-term effects of breast cancer surgery, treatment, and survivor care. J Midwifery Womens Health 64(6):713-724. https://doi.org/10.1111/jmwh. 13012

11. Hsieh H-F, Shannon SE (2016) Three approaches to qualitative content analysis. Qual Health Res 15(9):1277-1288. https://doi. org/10.1177/1049732305276687

12. Nolte S, Liegl G, Petersen MA, Aaronson NK, Costantini A, Fayers PM, Groenvold M, Holzner B, Johnson CD, Kemmler G, Tomaszewski KA, Waldmann A, Young TE, Rose M (2019) General population normative data for the EORTC QLQ-C30 health-related quality-of-life questionnaire based on 15,386 persons across 13 European countries, Canada and the Unites States. Eur J Cancer 107:153-163. https://doi.org/10.1016/j.ejca.2018.11. 024

13. van Leeuwen M, Husson O, Alberti P, Arraras JI, Chinot OL, Costantini A, Darlington A-S, Dirven L, Eichler M, Hammerlid EB, Holzner B, Johnson CD, Kontogianni M, Kjær TK, Morag O, Nolte S, Nordin A, Pace A, Pinto M, Polz K, Ramage J, Reijneveld JC, Serpentini S, Tomaszewski KA, Vassiliou V, Verdonck-de Leeuw IM, Vistad I, Young TE, Aaronson NK, van de Poll-Franse LV (2018) Understanding the quality-of-life (QOL) issues in survivors of cancer: towards the development of an EORTC QOL cancer survivorship questionnaire. Health Qual Life Outcomes 16(1):114. https://doi.org/10.1186/s12955-018-0920-0

14. Helm EE, Kempski KA, Galantino MLA (2020) Effect of disrupted rehabilitation services on distress and quality-of-life in breast cancer survivors during the COVID-19 pandemic. Rehabil Oncol 38(4):153-158. https://doi.org/10.1097/01.Reo.00000 00000000233

15. Miaskowski C, Paul SM, Snowberg K, Abbott M, Borno H, Chang S, Chen LM, Cohen B, Hammer MJ, Kenfield SA, Kober KM, Levine JD, Pozzar R, Rhoads KF, Van Blarigan EL, Van Loon K (2020) Stress and symptom burden in oncology patients during the COVID-19 pandemic. J Pain Symptom Manag. https://doi.org/ 10.1016/j.jpainsymman.2020.08.037

16. Spence RR, Sandler CX, Newton RU, Galvão DA, Hayes SC (2020) Physical activity and exercise guidelines for people with cancer: why are they needed, who should use them, and when? Semin Oncol Nurs. https://doi.org/10.1016/j.soncn.2020.151075

17. Gibbs L, Minnelli N, Larrivee J, Sahu KK, Siddiqui AD (2020) Oncology dietitians sound alarm in key nutrition needs of cancer patients during COVID-19 pandemic. JCO Oncol Pract 16(10):621-623. https://doi.org/10.1200/OP.20.00349

18. American Cancer Society; Survivorship: during and after treatment (2020) https://www.cancer.org/treatment/survivorship-during-and-after-treatment.html. Accessed 06.092020

19. Frey MK, Ellis AE, Zeligs K, Chapman-Davis E, Thomas C, Christos PJ, Kolev V, Prasad-Hayes M, Cohen S, Holcomb K, Blank SV (2020) Impact of the coronavirus disease 2019 pandemic on the quality-of-life for women with ovarian cancer. Am J Obstet Gynecol. https://doi.org/10.1016/j.ajog.2020.06.049

20. Paterson C, Gobel B, Gosselin T, Haylock PJ, Papadopoulou C, Slusser K, Rodriguez A, Pituskin E (2020) Oncology nursing during a pandemic: critical reflections in the context of COVID-19. Semin Oncol Nurs 36(3):151028. https://doi.org/10.1016/j.soncn. 2020.151028

21. Coles CE, Aristei C, Bliss J, Boersma L, Brunt AM, Chatterjee S, Hanna G, Jagsi R, Kaidar Person O, Kirby A, Mjaaland I, Meattini I, Luis AM, Marta GN, Offersen B, Poortmans P, Rivera S (2020) International guidelines on radiation therapy for breast cancer during the COVID-19 pandemic. Clin Oncol 32(5):279-281. https:// doi.org/10.1016/j.clon.2020.03.006

22. Chan A, Ashbury F, Fitch MI, Koczwara B, Chan RJ, MASCC Survivorship Study Group (2020) Cancer survivorship care during COVID-19-perspectives and recommendations from the MASCC survivorship study group. Support Care Cancer 28(8):3485-3488. https://doi.org/10.1007/s00520-020-05544-4

Publisher's note Springer Nature remains neutral with regard to jurisdictional claims in published maps and institutional affiliations. 